\title{
The Effect of Reduction Capability of Resin Material on the Solder Wettability for Electrically Conductive Adhesives (ECAs) Assembly
}

\author{
Jong-Min Kim, Kiyokazu Yasuda*, Masahiro Yasuda and Kozo Fujimoto \\ Department of Manufacturing Science, Graduate School of Engineering, Osaka University, Suita 565-0871, Japan
}

Electrically conductive adhesives (ECAs) have been developed as an alternative to traditional Sn-Pb solders for electronic and optoelectronic applications. However, there are critical limitations such as the low conductivity, and unstable contact resistance. These limitations have seriously hindered the broad applications of ECAs. In order to overcome these limitations, a new formulation using Pb-free conducting filler particles was proposed. Our previous study proved that the metallurgical interconnections among conducting filler particles and between particles and the conducting pads were established by process control. In particular, it was found that the wetting behavior of conducting fillers in ECAs is one of the main mechanisms for the establishment of conduction paths. In this study, we propose the fundamental concept of an assembly process using fusible $\mathrm{Pb}$-free conducting filler particles. Also, the effect of the reduction capability of base resin material on the solder wetting property was investigated. As candidates for ECA compositions, two types of resin materials and two lead-free solders were investigated. The reflow temperature profiles for each ECA formulation were determined using a differential scanning calorimeter (DSC) dynamic scan. The wettabilities of the lead-free solders were investigated using an optical microscope with a CCD camera and a microfocus Xray television system. It was found that the developed resin material with an intrinsic reduction capability shows good wettabilities in both leadfree candidates.

(Received September 22, 2003; Accepted January 21, 2004)

Keywords: assembly process, electrically conductive adhesive, lead-free solder, microelectronic and optoelectronic applications, reduction capability, wettability

\section{Introduction}

In recent years, the need for miniaturization, higher integration, higher performance and lower cost advanced electronic packages has grown. ${ }^{1,2)}$ Soldering technology using tin/lead solder alloys plays a crucial role in the manufacturing of electronics packaging. ${ }^{3)}$ It is used for solder-ball connections of ball-grid array (BGA) packages, flip-chip (FC) connections and in the assembly of surface mount technology (SMT) components on printed-circuitboards (PCB). As one of the primary components of eutectic solders, lead provides many technical advantages:4) 1$) \mathrm{Pb}$ reduces the surface tension of pure tin and eventually facilitates wetting, 2) $\mathrm{Pb}$ prevents the transformation of white tin to gray tin upon cooling past $286 \mathrm{~K}, 3) \mathrm{Pb}$ serves as a solvent metal, enabling the rapid formation of intermetallic bonds by diffusing in the liquid state. However, the global concerns of the toxicity and health hazard in solders have accelerated the elimination of $\mathrm{Pb}$ usage, due to the inherent toxicity of $\mathrm{Pb}$. In addition, the volatile solvents used to clean the flux residue cause the destruction of the ozone layer. ${ }^{5)}$ This has resulted in the search for lead-free alternatives to the conventional tin/lead solders and alternative joining processes for microelectronics applications. Two different groups of materials are being actively investigated for possible alternatives. One is lead-free solder alloys ${ }^{6,7)}$ and the other is electrically conductive adhesives (ECAs). ${ }^{8,9)}$ The present paper discusses the development and assembly of ECAs. There are various types of ECA formulations, including isotropic conductive adhesives (ICAs) and anisotropic conductive adhesives (ACAs), as shown in Fig. 1. ICAs consist of metallic particles and an organic binder with typical loadings of 25-30 volume \%, and are electrically conductive

*Corresponding author, E-mail: yasuda@mapse.eng.osaka-u.ac.jp (a)

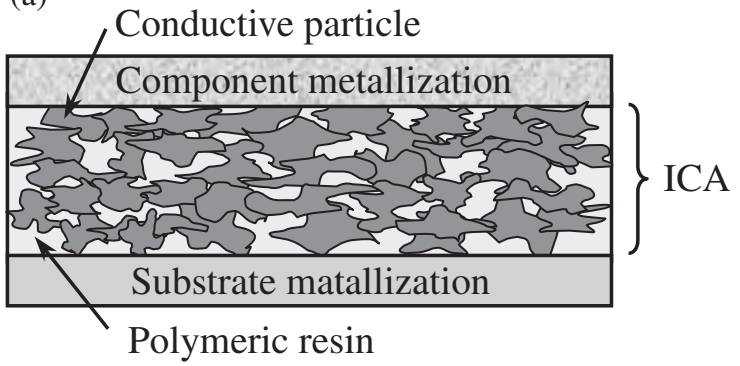

(b)

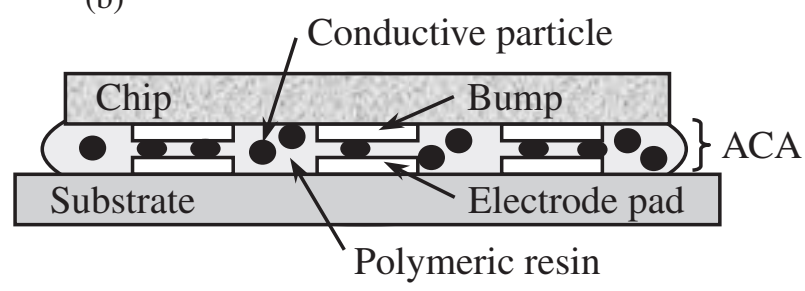

Fig. 1 Schematic of the internal structure of (a) isotropic conductive adhesives, and (b) anisotropic conductive adhesives.

in all directions. As a result, ICAs may be deposited only where electrical connections are actually required. ACAs have much lower metal contents of 5-20 volume \% and become conductive in one direction when compressed between two conducting pads. Conductive adhesives have the following potential advantages: ${ }^{10-12)}$ 1) lower process temperature enabling the use of heat-sensitive or nonsolderable materials, 2) higher resolution capability, 3) reduced environmental impact, and 4) improved processing characteristics. On the other hand, since the electrical conduction is obtained by mechanical/physical contact, several critical limitations such as low conductivity, unstable contact resistance, low joint strength, and silver migration 
have been found. ${ }^{13-15)}$ In order to overcome these drawbacks, our group has studied a hybrid of solder and conductive adhesive joining technologies to benefit from the advantages of both. In our previous work, ${ }^{16)}$ we reported on the preliminary results of a new class of conductive adhesives using fusible $\mathrm{Pb}$-free conducting filler particles, and polymer binder with an intrinsic reduction capability. Also, we could achieve different types of conduction paths according to the wetting and spreading characteristics in resin materials. In this study, the fundamental concept of the conductive adhesive assembly process was proposed. Four ECAs were formulated using two types resin materials and two lead-free alloys with low melting points. The proper reflow profiles for each ECA formulation were investigated by a differential scanning calorimeter (DSC). Wetting tests were conducted using each ECA formulation. The spreading and wetting angles were observed to investigate the effect of the reduction capability of the base resin material on the wettability in each ECA formulation. The results may contribute to an understanding of the mechanism of the conduction path formation, and to the establishment of the conductive adhesive assembly process using fusible solder filler particles.

\section{Fundamental Concept of the Conductive Adhesives Assembly Process}

The schematic of the conductive adhesives assembly process is shown in Fig. 2. The electrically conductive adhesive consists of a fusible $\mathrm{Pb}$-free conducting filler particle with a low melting point, a polymer binder, and other minor organic additives. Prior to reflow, the ECA is supplied locally or totally on the substrate and the chip is mounted on the ECA. During the initial stages of reflow, the ECA liquefies, and its viscosity decreases with increasing temperature. At this stage, the melted filler starts to wet on the surface of the conducting pads. Our previous work proved that it is important to control the process-related parameters such as the joint height $h$, the reflow temperature $T$, and the volume fraction of the filler particle $V_{\mathrm{f}}$. In this step (Fig. 2(b)), since the excessive curing progress of the resin materials reduces the wettability of the melted filler particles, the resin materials should not be cured too much before the melting point of the filler particle in order to achieve good wettability. This is critical for achieving reliable metallurgical interconnections such as those of solder joints. The wetting of filler particles initiates at the contact region between the particle and the conducting pad. Moreover, one of the critical requirements for a useful ECA formulation is to provide enough reduction capability during the reflow process. The reduction mechanism for organic acids can be expressed by the following reaction: ${ }^{17)}$

$$
2 \mathrm{RCOOH}+\mathrm{CuO} \rightarrow \mathrm{Cu}(\mathrm{RCOO})_{2}+\mathrm{H}_{2} \mathrm{O}
$$

The organic acids attack the oxide layer on both surfaces of the copper pad and the solder. Consequently, the reduction capability of the resin material helps to remove oxides from both the filler particles and the conducting pads, promoting the wetting of the filler particles to the pads. The fundamental concept of this process is that a more stable conduction path is established by using the wetting and spreading characteristics of filler particles in ECA during the reflow process.

\section{Experimental Procedure}

\subsection{Materials}

In order to investigate the effect of the reduction capability of the resin material on the wettability, a fusible filler particle was selected from a group consisting of $\mathrm{Cu}, \mathrm{Zn}, \mathrm{Ag}, \mathrm{Cd}$, In, $\mathrm{Sn}, \mathrm{Au}$, and $\mathrm{Bi}$. In this study, eutectic $\mathrm{Sn}-\mathrm{In}$ and $\mathrm{Sn}-\mathrm{Bi}$ solder balls with diameters of $1 \mathrm{~mm}( \pm 0.020)$ were used from Senju Metal Industry Co. Ltd. The chemical composition of the solder alloy is shown in Table 1. Based on a previous study ${ }^{18,19)}$ of the new ECA formulation, two kinds of resin material were used for the polymer binder and characterization. The two resin materials were named Resin A, and Resin B. Resin A is a blend of bisphenol A and bisphenol F
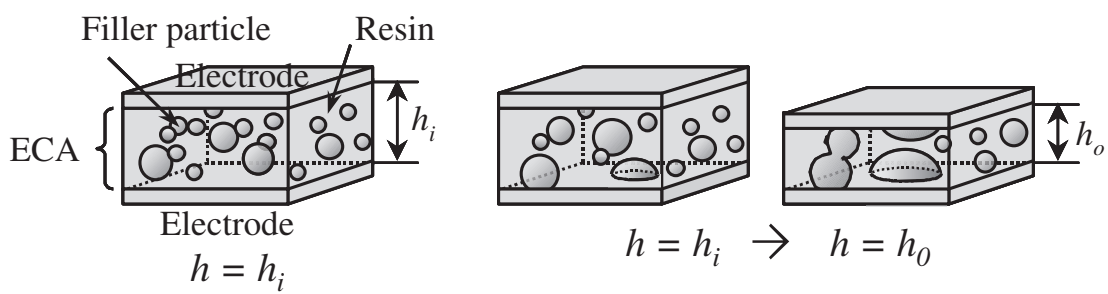

$$
h=h_{i} \rightarrow h=h_{0}
$$

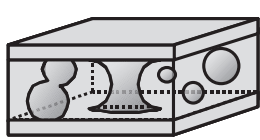

$$
h=h_{0}
$$

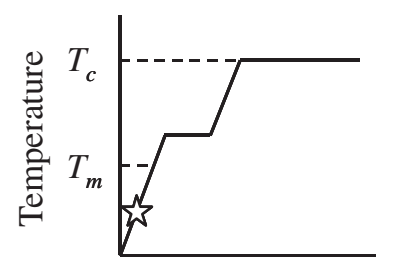

Time

$T<T_{m}$

(a)

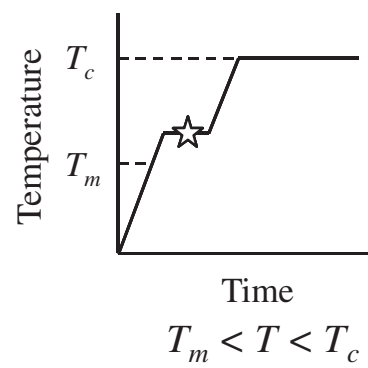

(b)

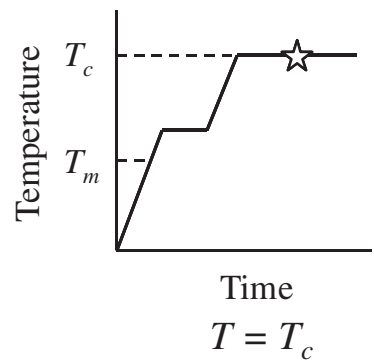

(c)

Fig. 2 Schematic of the conductive adhesives assembly process: (a) initial condition, (b) wetting and coalescence of filler particles during reflow, (c) establishment of conduction path. ( $T_{\mathrm{m}}$ : melting point of the filler particle, $T_{\mathrm{c}}$ : Curing temperature of the resin material). 
Table 1 Composition of solder alloy used in the experiment (mass\%).

\begin{tabular}{lccc}
\hline Solder alloy & Indium & Bismuth & Tin \\
\hline Sn-52In & 52.44 & - & bal. \\
\hline Sn-58Bi & - & 57.79 & bal. \\
\hline
\end{tabular}

Table 2 Material property of each resin material.

\begin{tabular}{lcccc}
\hline Material & $\begin{array}{c}\text { Specific } \\
\text { gravity }\end{array}$ & $\begin{array}{c}\text { Viscosity } \\
(\mathrm{Pa} \cdot \mathrm{s})\end{array}$ & $\begin{array}{c}\text { Resistivity } \\
(\Omega \cdot \mathrm{m})\end{array}$ & $\begin{array}{c}\text { Curing } \\
\text { condition }\end{array}$ \\
\hline Resin A & 1.23 & 2.6 & $6.0 \times 10^{13}$ & $453 \mathrm{~K} / 1 \mathrm{~h}$ \\
\hline Resin B & 1.20 & 8.0 & $5.5 \times 10^{13}$ & $453 \mathrm{~K} / 1 \mathrm{~h}$ \\
\hline
\end{tabular}

based on epoxy resin from Sanyu Rec Co. Ltd. Resin B is a special kind of bisphenol A-type epoxy resin dispersed with silicone cross-link particles from Sunstar Engineering Inc. ${ }^{20)}$ Since carboxylic acid with two or more carboxyl groups $(-\mathrm{COOH})$ in a molecule was used for the curing agent, it has an excellent fluxing effect against the surface oxide. It is also possible to inhibit the generation of void since it has no volatility. Their material properties are listed in Table 2.

\subsection{Solder wetting test}

To evaluate whether the resin materials can provide sufficient reduction capability, solder wetting tests were performed. For the conductive adhesive formulations, we examined four formulations (ECA-1 to ECA-4). Each formulation is shown in Table 3. A copper foil laminated FR-4 board was used as the substrate. The pad was designed to be sufficiently large to allow for the wetting of the solder. Figure 3 shows the pad configuration of the wetting speci-

Table 3 Each formulation of an electrically conductive adhesive used in the wetting test.

\begin{tabular}{clc}
\hline $\begin{array}{l}\text { Conductive } \\
\text { adhesive }\end{array}$ & $\begin{array}{l}\text { Resin } \\
\text { material }\end{array}$ & Solder alloy \\
\hline ECA-1 & Resin A & Sn-In \\
\cline { 1 - 1 } ECA-2 & Resin B & Sn-Bi \\
\hline ECA-3 & & Sn-In \\
\hline ECA-4 & & Sn-Bi \\
\hline
\end{tabular}

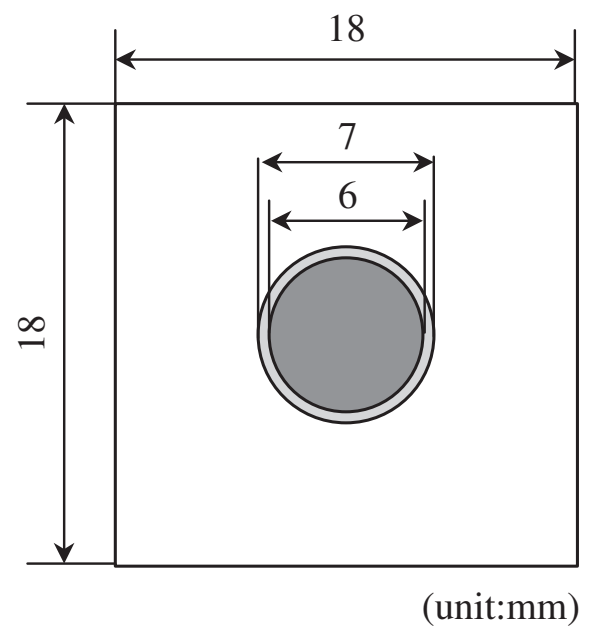

Fig. 3 Pad configuration of the wetting specimen. men. The specimens were cleaned using the following procedure: 5 minutes of ultrasonic cleaning with acetone, followed by a DI water rinse, 30 seconds of etching in a $6 \%$ $\mathrm{HCl} / \mathrm{H}_{2} \mathrm{O}$ solution to remove the surface oxide, followed by a DI water rinse and air-jet drying. Prior to the wetting test, we conducted a differential scanning calorimeter (DSC) study in order to investigate the curing behaviors of resin materials and the melting of the solder balls. The liquid resin samples and the solder balls were heated in an aluminum pan to $473 \mathrm{~K}$ in a DSC instrument (PerkinElmer; DSC-7) at a heating rate of $5 \mathrm{~K} / \mathrm{min}$ under an argon purge gas atmosphere. Based on the results of DSC analysis, proper reflow profiles were determined. For a wetting experiment, a solder ball was placed on a pad. Then, an amount of liquid resin was applied to immerse the solder ball. The test vehicles were then reflowed on the uniform heating vessel (Sanyoseiko Co. Ltd.; SA-5000) with the desired profile in an air atmosphere. The spreading of the solder melt on the copper board was observed using the microfocus X-ray television system (Shimadzu Co.; SMX-1160E). The reflowed solder ball was then cross-sectioned using a diamond saw, and the wetting angle was evaluated quantitatively using an optical microscope with a CCD camera.

\section{Results and Discussion}

The curing behaviors of the resin materials employed and the melting behaviors of the lead-free solders used in this study are shown in Fig. 4. As can be seen from this figure, the curing peak temperatures of each resin material were about $399 \mathrm{~K}$ for resin A, and about $414 \mathrm{~K}$ for resin B. They showed relatively low-temperature curing characteristics compared to those of conventional silver-filled conductive adhesives. Also, it can be seen that the endothermic peak temperatures were about $394 \mathrm{~K}$ for the Sn-In solder alloy, and about $418 \mathrm{~K}$ for the Sn-Bi solder alloy, and the resin materials did not show significant curing at these temperatures. As previously mentioned, a proper reflow profile must be selected for the melted solder to more quickly wet and spread than the curing of the resin materials. Otherwise, the wetting and spreading behaviors are hindered due to the excessive curing progress of the resin materials. Based on these results of the DSC dynamic scan analysis, the reflow profiles for each sample

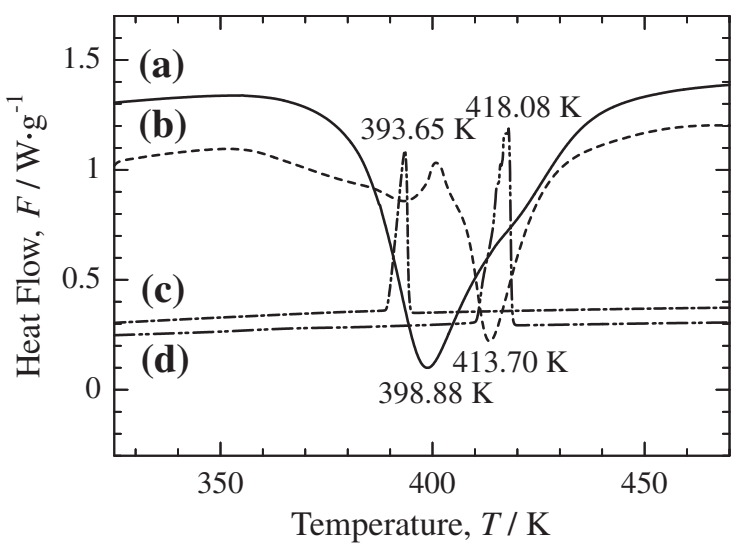

Fig. 4 DSC dynamic scan of (a) Resin A, (b) Resin B, (c) Sn-52In alloy, and (d) Sn-58Bi alloy at a heating rate of $5 \mathrm{~K} / \mathrm{min}$. 


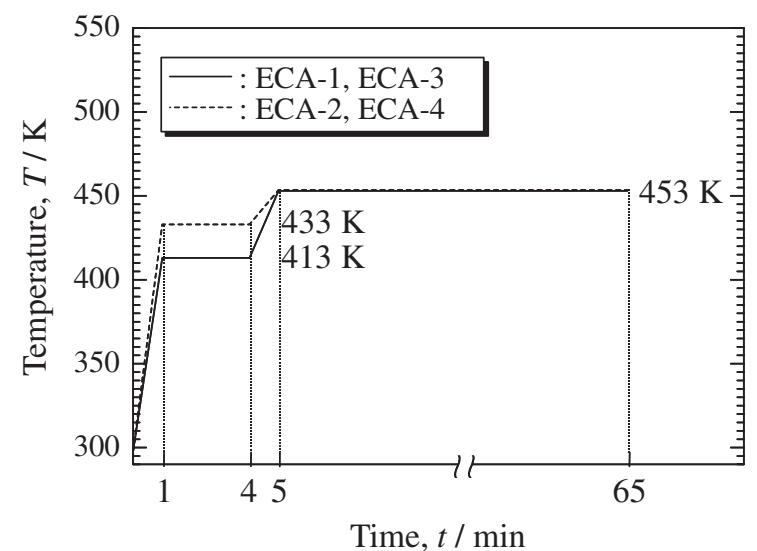

Fig. 5 Reflow temperature profile for each ECA formulation.

were developed as shown in Fig. 5. As shown in the figure, in order to ensure that each solder melts and wets, the test vehicles were heated from ambient temperature to a temperature of about $15 \sim 20 \mathrm{~K}$ higher than the peak point of each solder alloy. In addition, we set the ramping time to 1 minute to this temperature in order to avoid the excessive curing progress of each resin material. Then, the test vehicles remained at this temperature for 3 minutes, followed by a heating to $453 \mathrm{~K}$ for 1 minute and a curing time of 60 minutes. After this, the test vehicles were reflowed with this developed reflow profile, and the spreadings of the solder alloys were inspected using the X-ray equipment. Figure 6 shows an X-ray picture of the spreading of each ECA formulation where the white circle represents the size of the non-melted solder ball. As shown in the figure, both the Sn-In and $\mathrm{Sn}-\mathrm{Bi}$ solder alloys hardly spread at all when resin A was used as the polymer binder. When using resin B, however, both solder alloys showed good spreading behavior due to their reduction capability. The difference in the spreading areas between the Sn-In solder alloy and the Sn-Bi solder alloy was not remarkable. The radius of the basis area $b$ and the spread area $A$ were about $0.82 \mathrm{~mm}$, and $2.11 \mathrm{~mm}^{2}$, respectively. If the spreading of a solder alloy is assumed to remain a spherical cap, the volume of the spread solder $V$ can be expressed as a function of the radius of the basis area $b$ and the wetting angle $\theta$, which is given by Klein-Wassink: ${ }^{21)}$

$$
V=\frac{\pi b^{3}}{6}\left\{\left(\tan \frac{\theta}{2}\right)^{3}+3 \tan \frac{\theta}{2}\right\}
$$

As the spread of the solder volume can be assumed to be the volume of the solder ball $\left(=(4 / 3) \pi r^{3}\right)$ before the reflow process, eq. (1) may be rearranged to show the relationship between the radius of the solder ball and the contact angle:

$$
\left(\frac{r}{b}\right)^{3}=8\left\{\left(\tan \frac{\theta}{2}\right)^{3}+3 \tan \frac{\theta}{2}\right\}
$$

From this relationship, the wetting angles could be predicted, and were about 32 degrees. In order to investigate the extent of solder wetting in the resin material, the wetting angle was inspected. Figure 7 shows the optical cross-section microscope of the solder wetting in resin A. As expected in the Xray inspection, solder wetting almost did not occur. In general, wetting is possible only if the solder can come into immediate contact with the metallic surface of the conducting pad. Any contamination such as oxides on the surface to be soldered will act as a barrier to metallic continuity and thus prevent wetting. As resin A has no reduction capability, the solders did not wet due to the oxides remaining on the surface of the solders and the conducting pads. In a previous work, it was proved that the ECA-1 formulation using resin A wet locally and a necking-type conduction path was formed. This type of conduction path may be explained by preventing the wetting and the spreading as shown in the wetting test. This was mainly caused by the remaining surface oxide films of both the solder alloys and the conducting pad.

On the other hand, as shown in Fig. 8, both the Sn-In alloy in the ECA-3 and the Sn-Bi alloy in the ECA-4 with Resin B showed good wettability. During the reflow process, the resin materials began to soften at a temperature of around $373 \mathrm{~K}$, and flowed. For resin B, it could be observed that the solder alloys melted, wet and spread with increasing reflow temperature. Resin B showed an excellent fluxing effect in contrast with resin A. Also, this fluxing action was effective for wetting and spreading the Sn-In and Sn-Bi solder alloy, especially, in each of the ECA formulations. A good metallurgical interconnection between the fusible filler particles and between the particles and the conducting pads is expected. For a quantitative comparison of the wetting angle, Fig. 9 shows the wetting angle measured using the cross-section picture of each ECA formulation. The wetting angle in each ECA formulation was the average of both ends of the four samples. As shown in the results, the solder alloys in resin A did not wet and the wetting angles were about $156.8 \mathrm{deg}$ for the Sn-In solder, and about $152.3 \mathrm{deg}$ for the $\mathrm{Sn}-\mathrm{Bi}$ solder. On the other hand, the wetting angles in resin B were much smaller than those in resin A. The wetting angles were about $35.4 \mathrm{deg}$ and $34.1 \mathrm{deg}$ for $\mathrm{Sn}$-In and $\mathrm{Sn}$-Bi solder, respectively. Also, it can be seen that the fluxing capacity of resin $\mathrm{B}$ on the $\mathrm{Sn}-\mathrm{Bi}$ solder alloy was slightly better than that on the Sn-In solder alloy. The report reviewed by Abtew et $a l .{ }^{4)}$ on the wettability of lead-free solders is most useful for comparing the wetting angle of different alloys, because they were all measured using the same flux. They reported that the wetting angles on the copper substrate using A611 flux were $63 \pm 6 \mathrm{deg}$ at $488 \mathrm{~K}, 41 \pm 9 \mathrm{deg}$ at $503 \mathrm{~K}$, and $33 \pm 5 \mathrm{deg}$ at $518 \mathrm{~K}$ for Sn-50In solder, and $43 \pm 8 \mathrm{deg}$ at $468 \mathrm{~K}$ for $\mathrm{Sn}-$ $58 \mathrm{Bi}$ solder. A meaningful comparison of the performance based on such measures as the wetting angle of the alloys is difficult because of the experimental variables such as the temperature of measurement, the surface condition of the substrates, and the fluxes used. However, the results observed in this study showed good wettability compared to those of other reports using fluxes. ${ }^{4,22,23)}$ It can be also concluded that resin $\mathrm{B}$ has an effective reduction capability on the candidate fusible lead-free solders of Sn-In and Sn-Bi solder alloy.

\section{Conclusions}

The wetting and spreading characteristics of filler particles in the ECA formulations are critical in achieving metallurgical interconnections during assembly processes. Two epoxy-type resin materials were investigated as polymer 

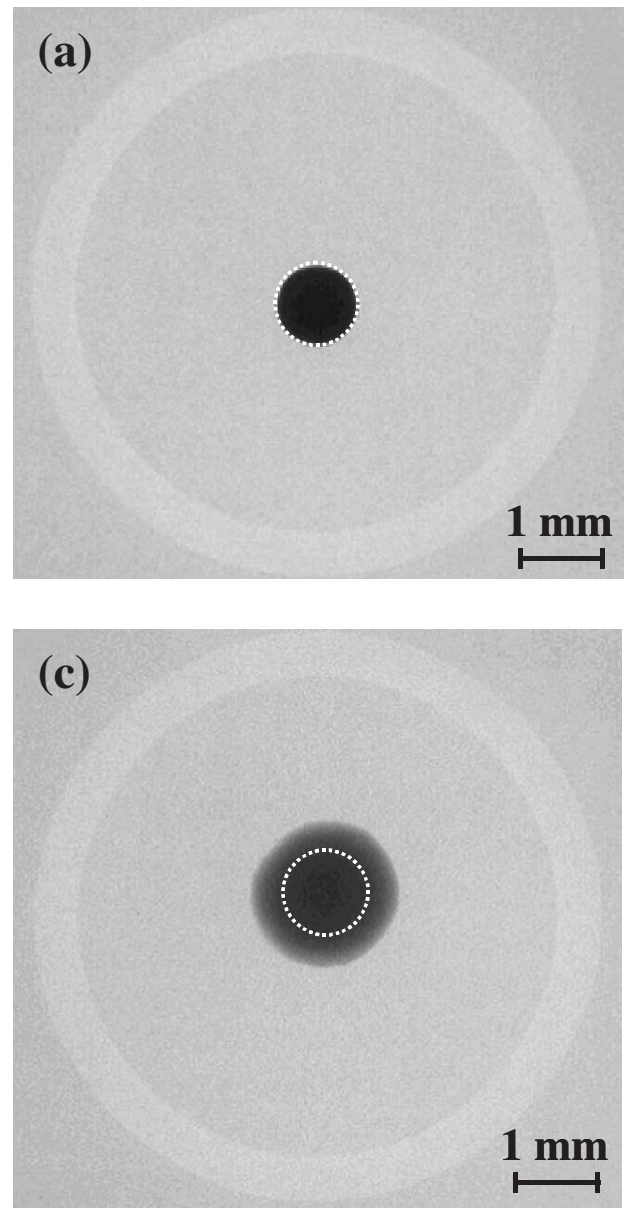

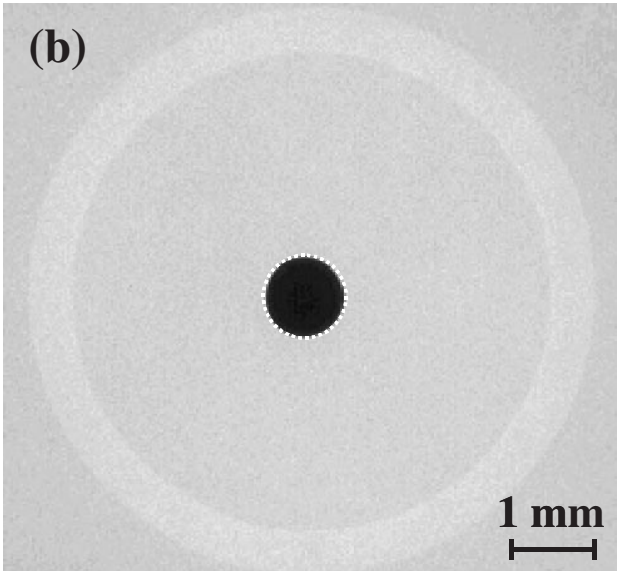

(d)

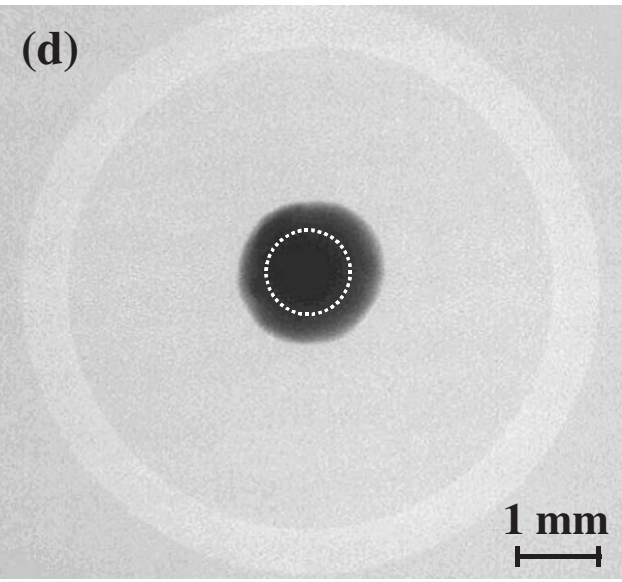

Fig. 6 X-ray image of spreading of (a) ECA-1, (b) ECA-2 using resin A, (c) ECA-3, and (d) ECA-4 using resin B.
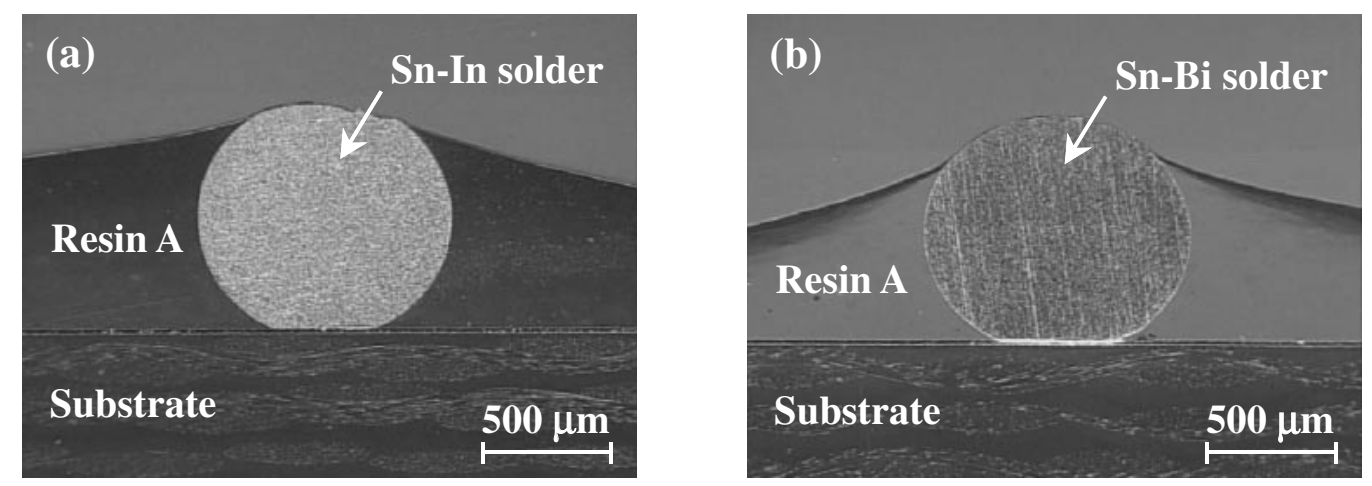

Fig. 7 Optical cross-section micrograph of (a) ECA-1 and (b) ECA-2 using resin A.

binders, and two lead-free solders (Sn-42In, Sn-58Bi) with low melting points were examined as potential filler alloy materials. The developed polymer binders were characterized using DSC dynamic scans, and the proper reflow profiles were developed. As one of the main mechanisms, the solder wetting test was conducted, and the results proved that the resin B developed has excellent reduction capabilities for each of the lead-free solders to wet onto the non-noble copper conducting pad during the reflow process. There was evidence for the wetting of both the Sn-In and Sn-Bi alloys in resin A through the X-ray inspection of the solder spreadings. However, the spread areas and the radius of the basis area for both of the solder alloys in resin B with its intrinsic reduction capability enlarged by about 2.6 times $\left(2.11 \mathrm{~mm}^{2}\right)$ and 1.6 times $(0.82 \mathrm{~mm})$, respectively, compared to the size of the original solder balls used. The average wetting angle of the Sn-In solder in ECA 3 was about $35.4 \mathrm{deg}$, while the corresponding value of the $\mathrm{Sn}-\mathrm{Bi}$ solder in ECA 4 was about $34.1 \mathrm{deg}$. Although the difference in the wettability between the $\mathrm{Sn}$-In solder and the Sn-Bi solder in resin B was not significant, it could be observed that the reduction capability on the $\mathrm{Sn}-\mathrm{Bi}$ solder was slightly more effective compared to that on the Sn-In solder. 

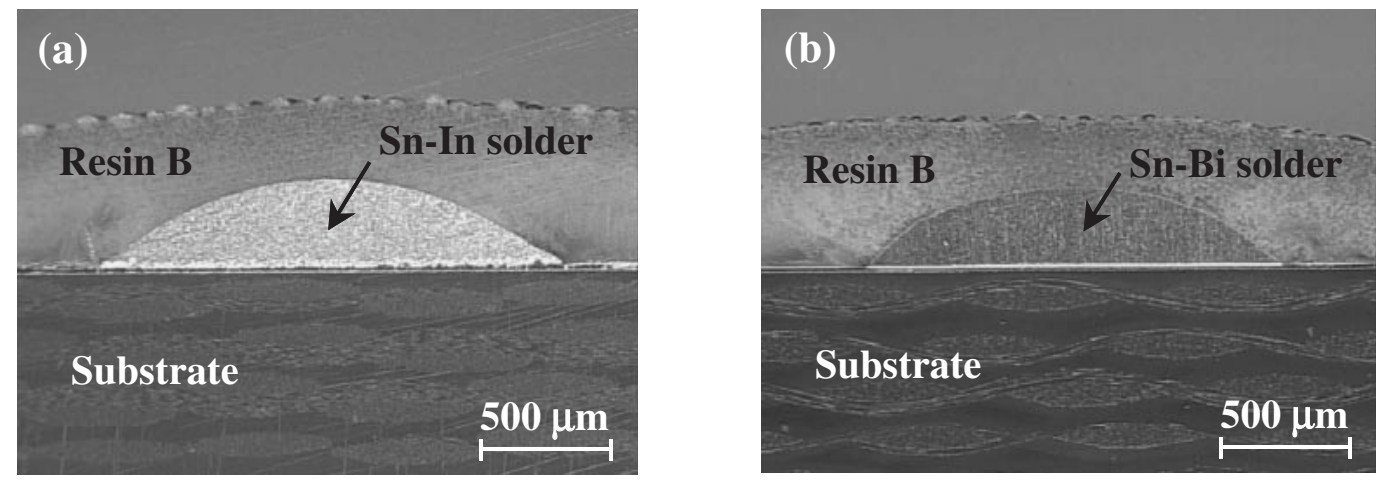

Fig. 8 Optical cross-section micrograph of (a) ECA-3 and (b) ECA-4 using resin B.

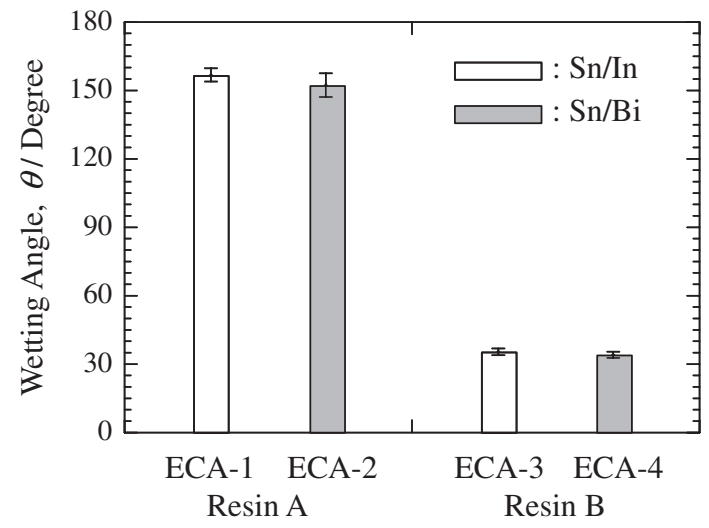

Fig. 9 Wetting angles of the Sn-In and Sn-Bi solders in each resin material.

\section{Acknowledgements}

This work was supported by "Priority Assistance of the Formation of Worldwide Renowned Centers of Research - The 21st Century COE Program (Project: Center of Excellence for Advanced Structural and Functional Materials Design)" from the Ministry of Education, Sports, Culture, Science and Technology of Japan.

\section{REFERENCES}

1) I. Anjoh, A. Nishimura and S. Eguchi: IEEE Trans. Electron Devices 45 (1998) 743-752.

2) R. Nair: IBM J. Res. \& Dev. 46 (2002) 223-234.

3) A. Rahn: The Basics of Soldering, (John Wiley \& Sons, 1993) 1-102.

4) M. Abtew and G. Selvaduray: Mater. Sci. and Engineer.: R: Rep. 27 (2000) 95-141.

5) C. B. Park, S. M. Hong, J. P. Jung, C. S. Kang and Y. E. Shin: Mater.
Trans. 42 (2001) 820-824.

6) R. R. Tummala, E. J. Rymaszewski and A. G. Klopfenstein: Microelectronics Packaging Handbook-Subsystem Packaging Part III, (Chapman \& Hall, 1997) 217-223.

7) K. Suganuma: Current Opinion in Solid State and Mater. Sci. 5 (2001) 55-64.

8) J. Liu, Z. Lai, H. Kristiansen and C. Khoo: Proc. 3rd Int. Conf. on Adhesive Joining and Coating Technol. In Elec. Manufac. (1998) 1-18.

9) J. Liu: Conductive Adhesives for Electronics Packaging, (Electrochemical Publications Ltd., 1999).

10) J. C. Jagt, P. J. M. Beris and G. F. C. M. Lijten: IEEE Trans. Comp. Packag. Manufac. Technol.-Part B 18 (1995) 292-298.

11) D. Lu and C. P. Wong: Proc. Int. Sym. on Advanced Packag. Mater. (1999) 288-294.

12) D. Wojciechowski, J. Vanfleteren, E. Reese and H.-W. Hagedorn: Microelectronics Reliability 40 (2000) 1215-1226.

13) M. Zwolinski, J. Hickman, H. Rubin, Y. Zaks, S. McCarthy, T. Hanlon, P. Arrowsmith, A. Chaudhuri, R. Hermansen, S. Lau and D. Napp: IEEE Trans. Comp. Packag. Manufac. Technol.-Part C 19 (1996) 241250.

14) J. C. Jagt: IEEE Trans. Comp. Packag. Manufac. Technol.-Part A 21 (1998) 215-225.

15) D. Lu, Q. K. Tong and C.P. Wong: IEEE Trans. Electron. Packag. Manufac. 22 (1999) 228-232.

16) J. M. Kim, K. Yasuda, M. Rito and K. Fujimoto: Mater. Trans. 45 (2004) 157-160.

17) S. H. Shi, D. Lu and C. P. Wong: 1999 Int. Sym. on Advanced Packag. Mater. (1999) 325-332.

18) K. Yasuda, J. M. Kim, M. Rito and K. Fujimoto: 2003 Int. Conf. on Elec. Packag. (2003) 149-154.

19) K. Yasuda, J. M. Kim, M. Rito and K. Fujimoto: 3rd Int. IEEE Conf. on Polymer and Adhesives in Microelec. and Photon. (2003) 5-10.

20) J. Goto and T. Okuno: J.P. Patent (disclosing) P2002-293883A.

21) R. J. K. Wassink: Soldering in Electronics, (Electrochemical Publications Ltd., 1989) 36-83.

22) A. M. Jackson, P. T. Vianco and I. Artaki: Proc. 7th Int. SAMPE Electro. Conf. (1994) 381-391.

$23)$ C. B. Lee, S. B. Jung, Y. E. Shin and C. C. Shur: Mater. Trans. 42 (2001) 751-755. 